\title{
Information technologies for landslides and mudflows research
}

\author{
Bolotbek Biibosunov ${ }^{I^{*}}$, and Jenish Beksulanov ${ }^{l}$ \\ ${ }^{1}$ Kyrgyz State University named after I. Arabaev, 51A Razzakov Street, Bishkek, 720000, \\ Kyrgyzstan
}

\begin{abstract}
This article presents the results of research using computer technology and mathematical modeling in relation to hydrodynamic processes that determine such natural disasters as landslides and mudflows common in the territory of the Kyrgyz Republic. A specialized website is proposed, which contains the results of scientific research on natural and manmade disasters and exogenous geological processes (EGP). The following systems were used as the main database management systems (DBMS): MS Access, My SQL and PostgreSQL. Thus, the main means of developing computer programs and computational procedures are Delphi, Python, Visual Basic, Java and JavaScript. Web technologies and the following software tools were used to design and create the site: Python, JavaScript, PhP and HTML. Modern level of scientific research presumes and obliges development and using of new information technologies. In this regard there was defined a problem on mathematical modelling and information technologies using for research and forecasting of EGP on the territory of Kyrgyzstan. There are proposed hydrodynamic models and numerical methods of their solution. Information system is developed for landslides, mudflows, and other EGP types, typical for Kyrgyzstan.
\end{abstract}

\section{Introduction}

As reported by the Ministry of Emergency of the Kyrgyz Republic, there are currently about 5,000 modern landslides on the territory of the Kyrgyz Republic. Landslides are developed mainly in low-and mid-mountain zones coinciding with the area of distribution of meso-Cenozoic sediments represented by interlayer variegated clays, sandstones, limestones, marls, gypsum with multiple aquifers and loess-like loam. Due to the activation of interacting modern geodynamic movements, seismicity, rise of groundwater level, abnormal amount of precipitation, as well as engineering and economic activity of man in mountain areas, the number of landslides increases annually [1, 6, 9, 23].

“...During 2015, the number of intensified landslides amounted to 11 occurrence in Jalal-Abad, Batken, Osh, Naryn region and the city of Osh. Due to predictive data the reliability of the place of activation of landslides is up to $85 \%$, and in terms of capacity and expected time up to $85 \%$..."[23].

\footnotetext{
* Corresponding author: bbolotbek@mail.ru
} 
Mudflow processes and phenomena in the course of 2015 amounted to 75 occurrences. With regard to the reliability of the forecast of mudflows, at the place of mudflows passage, the reliability is up to $85 \%$, and due to the expected capacity and time of activation of mudflows up to $85 \%$.

Table 1. Data on disasters of the National Statistical Committee of the Kyrgyz Republic

\begin{tabular}{|l|l|l|l|l|l|l|l|l|l|l|}
\hline Years & $\mathbf{2 0 0 6}$ & $\mathbf{2 0 0 7}$ & $\mathbf{2 0 0 8}$ & $\mathbf{2 0 0 9}$ & $\mathbf{2 0 1 0}$ & $\mathbf{2 0 1 1}$ & $\mathbf{2 0 1 2}$ & $\mathbf{2 0 1 3}$ & $\mathbf{2 0 1 4}$ & $\mathbf{2 0 1 5}$ \\
\hline $\begin{array}{l}\text { Mudflows } \\
\text { and floods }\end{array}$ & 33 & 70 & 83 & 93 & 131 & 61 & 217 & 65 & 42 & 75 \\
\hline landslides & 13 & 5 & 2 & 13 & 40 & 12 & 17 & 9 & 3 & 11 \\
\hline
\end{tabular}

In addition, natural emergencies include dangerous meteorological phenomena (rainfall, hail, strong winds, snowfall and frost, drought, etc.), erosion of banks, and subsidence in loess and clay soils, avalanches, rock falls and others.

\section{Materials and methods}

This paper proposes a specialized website that contains the results of scientific research on natural and manmade disasters, exogenous geological processes (EGP), possible breakthrough turbulent flows that pose a threat to hydraulic structures and other national economic and technical facilities, communications, etc.

Figure 1 shows the main page of the website, for the design and development of which, modern software tools were used. Thus, Delphi, Python, Visual Basic, Java and JavaScript are the main means of developing computer programs and computational procedures. Web technologies and the following software tools, as: Python, JavaScript, $\mathrm{PhP}$ and HTML were used to design and create the website $[2,3,4,5]$.

Because tables can take many forms, it is difficult to provide detailed guidelines; however, the following examples demonstrate our preferred styles.

The following systems: MS Access, My SQL и PostgreSQL were used as the major database management systems (DBMS) [21, 22].

On the top panel of the site is the main menu, which contains the following headings: "Home", "EGP in the Kyrgyz REPUBLIC", "EGP modeling", "Predictive models", " Information systems and databases». 
Home page

Exogenous geological processes in the Kyrgyz Republic

Due to the peculiarities of the mountain-geological and tectonic structure of the mountainous terrain, almost the entire territory of the Kyrgyz Republic is subject to exogenous geological processes (EGP), such as landslides, mudflows, aval anches, landslides, earthquakes.

The most catastrophic manifestations among other exogenous geological processes are landslides and mudflows. Landslides and mudflows are one of the most widespread types of natural catastrophic phenomena that cause enormous destruction in large areas, lead to enormous loss of life, and cause great damage to the economy and the environment. Mudflows and landslides are widespread throughout Kyrgyzstan and, especially, in the southern regions: Osh, Jalal-Abad and Batken regions. Almost every year, due to the intensification of landslides and mudflows, Kyrgyzstan suffers large material losses. Many years of bitter experience show that these natural catastrophic processes cause enormous economic damage to the national economy, cause deaths,

Emergencies throughout the history have a noticeable negative impact on the development of life, lead to mass deaths, cause enormous, direct and indirect damage to the economy of states. Many catastrophic processes are closely related and interconnected with each other and cause multistage spontaneous processes and phenomena.

In Kyrgyzstan, landslide and mudflow processes often began to occur in the mountainous regions of the republic. which lead to the need to study the causes of the origin of these natural phenomena, as well as determine the basic physical and mathematical parameters and their properties.

Due to climatic and geological and geographical conditions, many problems arise that are an integral part of the national strategy for sustainable development of the mountainous territories of the Republic. One of such problems is landslide processes and mudflows, which often occur in the southern regions of Kyrgyzstan (Osh, JalalAbad, Batken regions) and they are catastrophic natural phenomena.

Fig. 1. Home page of the web page.

Let's review the section "Exogenous geological processes in the Kyrgyz Republic." This section presents the main EGP, types of natural and man-made disasters on the territory of the country (Figure 2).

Exogenous geological processes in the Kyrgyz Republic.

The intensification of mudslides and landslides, which are often catastrophic, cause great damage to localities, engineering and technical communications, the economy of the country, and are accompanied by human sacrifice. In this regard, the actual task is to monitor the EGP using modern scientific tools [7, 8, 10, 12].

The geological structure and topography are permanent factors. They determine the genetic characteristics of EGP, as well as the intensity of their manifestation. These factors are to be needed condition for the formation of exogenous-geological processes, and are considered as constant.

Modern tectonic movements, climatic locality characteristics, hydrogeological conditions, flora and others belong to the second group of factors $[13,15,16]$.

Third group of factors consist of meteorological, hydrological, and also seismic and technological processes. Current group of factors is the basis for interim forecast of the studied processes, set of factors of the first and the second group is the basis of dimensional EGP forecasting. 


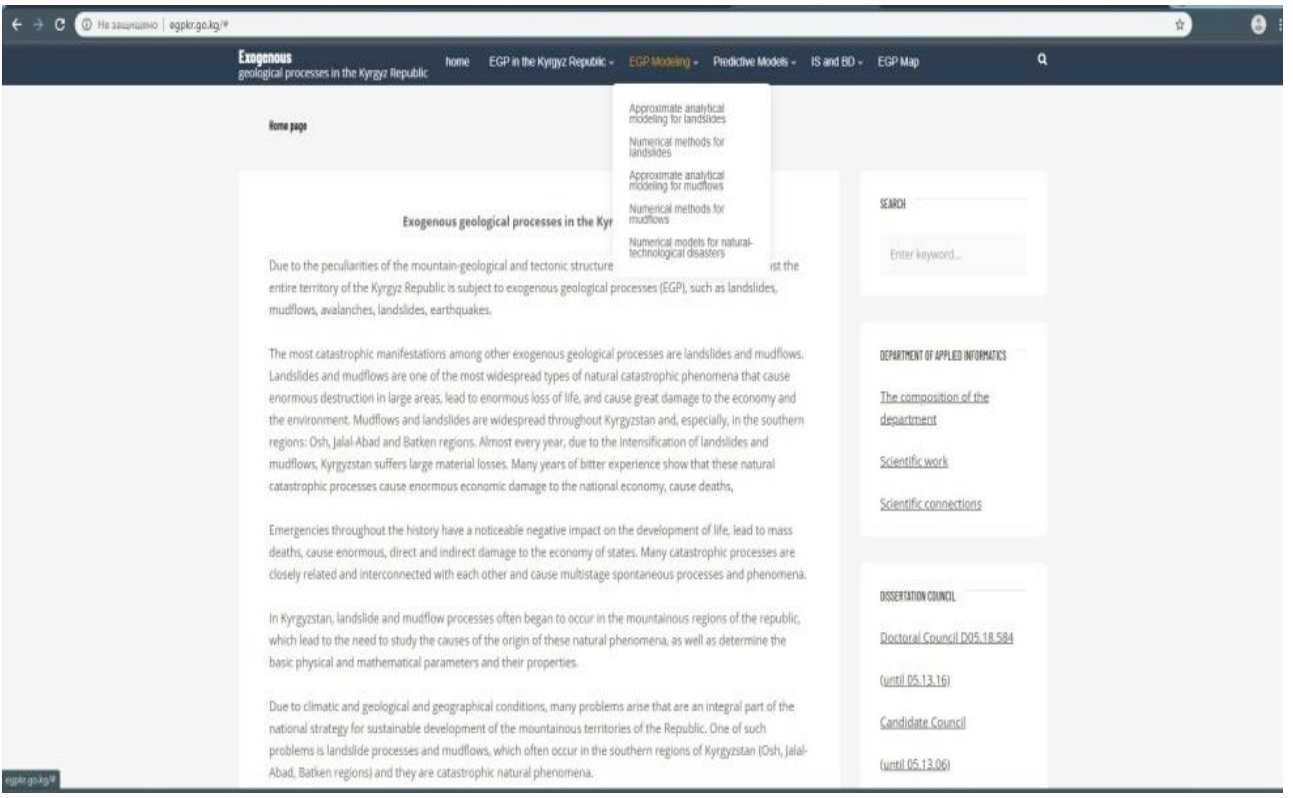

Fig. 2. EGP and its modelling.

EGP Modelling.

This section presents mathematical models for the studied EGP, as well as various initial-boundary value problems for hydrodynamic processes and flows in different environment.

Herein the following large classes of scientific problems are considered: modeling of landslide processes by using approximate analytical methods of solution; numerical mathematical models of landslide flows based on computational methods of applied mathematics and computational fluid dynamics;

simulation of mudflow processes by using approximate analytical methods of solution; models for catastrophic mudflows based on numerical methods and computational algorithms; development of models for natural and man-made disasters based on numerical methods and algorithms $[11,16,17]$.

Current section of research is devoted to the forecasting of natural disasters in the Republic based on the theory of correlation-regression and factor analysis. The website also has a section "Forecasting models".

\section{Research results}

It is depicted that hydrodynamic processes, fluid filtration (groundwater and underwater) and fluid infiltration (precipitation, surface runoff, snowmelt, etc.) in landslides and mudslides are among the main factors of the emergence, formation and activation of EGP in our country.

As you know, an important practical task is to determine the probable slip line of landslides. In this regard, the problem of fluid filtration in inhomogeneous-anisotropic soil is formulated and solved in the form of a second order partial differential equation with Dirichlet and Neumann type boundary conditions at an unknown boundary sliding line of landslides. To solve this half-inverse boundary value problem, a well-known numerical finite element method is applied in two-dimensional and three-dimensional 
formulation with an iterative procedure for finding an unknown boundary-a line or a sliding plane $[18,19,20]$.

Based on the solution of boundary value problems of filtration and infiltration of liquid there is put the problem of determination of stability of slopes against a landslide taking into account the main physical forces and the loadings acting on a landslide slope. After the loss of landslide slope stability caused by a set of core factors activation of landslides occurs and for landslide - flows, landslides, mud-stone flows there are developed models of two-phase unsteady flows with initial-boundary conditions of Cauchy-type integrals, Dirichlet and Neumann, and mixed conditions by using the theory of "shallow water" and the theory of turbulent flows. The large particle numerical method is used to solve these nonlinear models.

Linear and nonlinear forecasting models are proposed based on the theory and methods of regression and factor analysis for EGP predicting. Time series of activation of landslides and mudflows and other major factors are based on observations of the Ministry of Emergency and the Kyrgyz Hydrometeorological Agency (data by year, quarter, month and landslide and mudslide-prone areas and sites).

The information system for EGP on the territory of Kyrgyzstan has been developed, the database of which contains the necessary information used for modeling and EGP forecasting. Figure 3 presents the information system installation and startup window and the main menu.

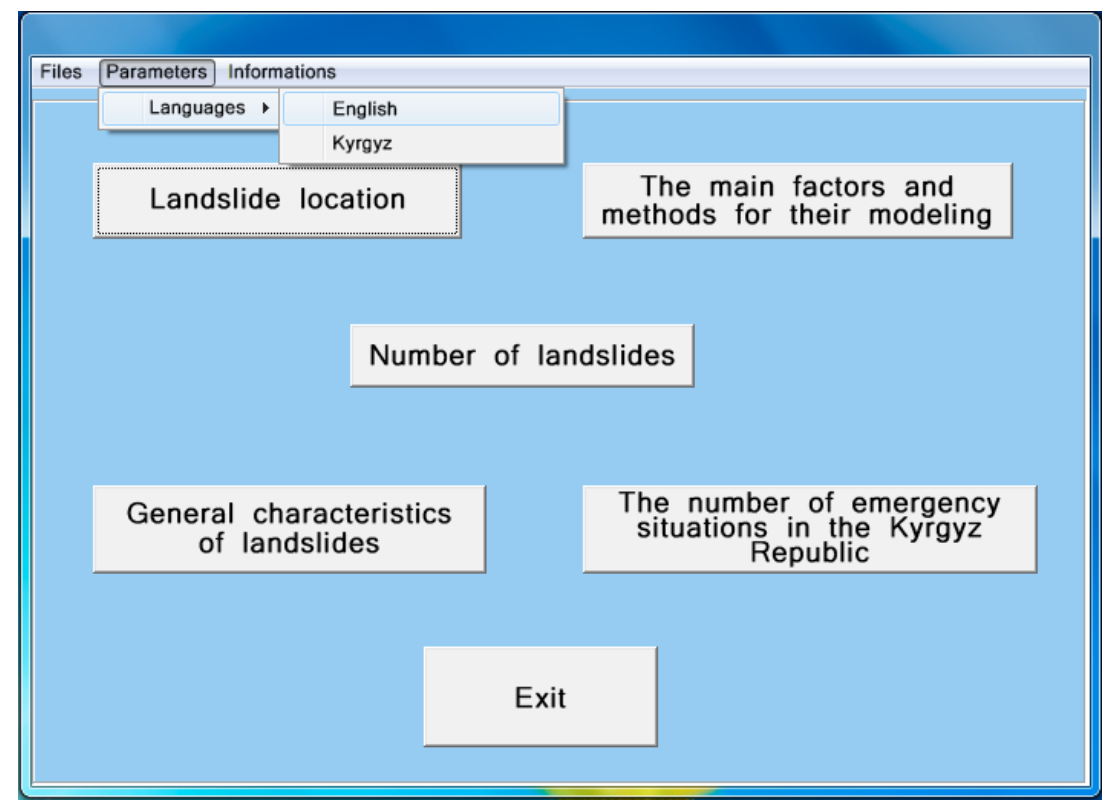

Fig. 3. Main menu of the information system.

In order to develop and create mathematical tool for monitoring dangerous EGP, we'll be presenting test problems as mathematical models that are described by parabolic and hyperbolic equations with corresponding initial and boundary conditions, and for which numerical methods and algorithms are used. Numerical methods and algorithms are implemented by using Python and built-in mathematical libraries, as well as graphical representation and display tools.

We will consider the processes described and modeled by a parabolic equation (transfer problems). The mathematical statement of the problem will be written as follows: 


$$
\frac{\partial U(x, t)}{\partial t}+c \frac{\partial U(x, t)}{\partial x}=\Phi(U, x, t)
$$

To solve the mathematical model, the finite difference method is used and a well-known explicit difference scheme is used:

$$
\frac{\hat{U}_{i}-U_{i}}{\tau}+c \frac{U_{i}-U_{i-1}}{\Delta}=\frac{\Phi_{i-1}+\Phi_{i}}{2}
$$

where $\mathrm{U}^{\wedge}$ - is the value of the grid function on the upper time layer.

By using the standard procedures of the Python mathematical library and the graphical editor tools, we obtain the following numerical solutions, which are shown in fig. 4.
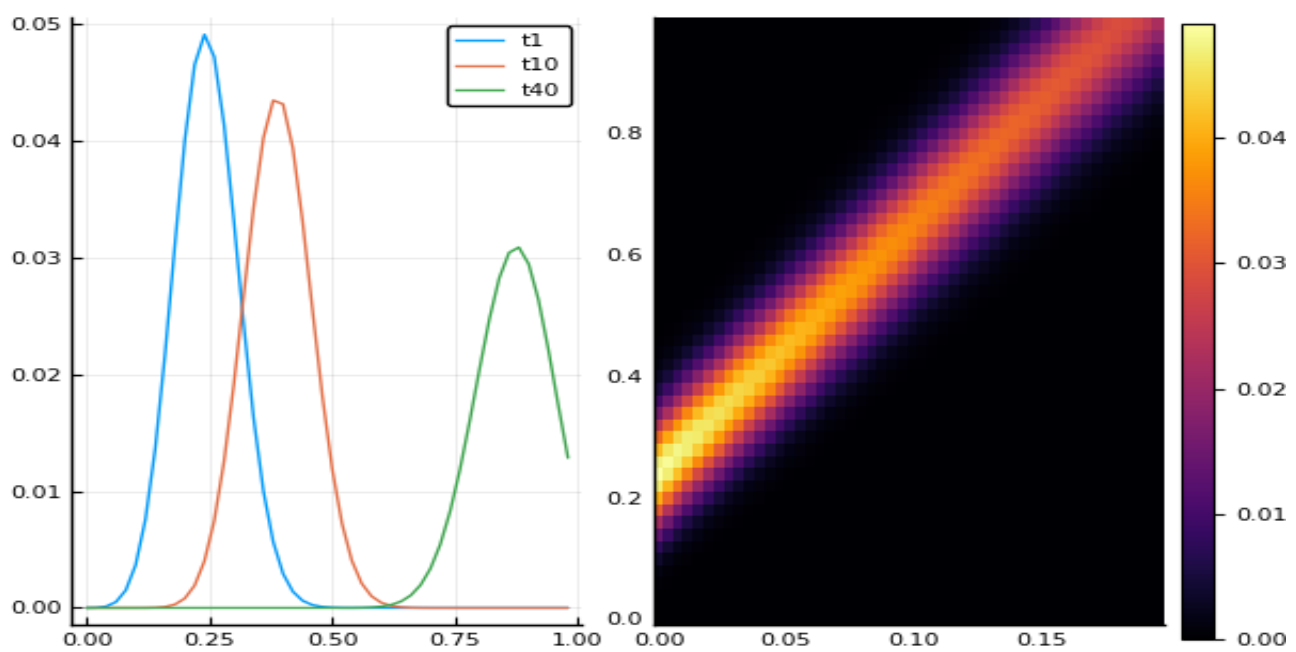

Fig. 4. Numerical solutions of the transfer equation for the linear case

(at the $y$-axis is the value of the $u$ function, and at the $\mathrm{x}$-axis is the time. On the right is a color map of solution graphs)

We will review the following mathematical model while analyzing nonlinear transposition. The model will be written as follows:

$$
\frac{\partial U(x, t)}{\partial t}+\left(C_{0}+U C_{1}\right) \frac{\partial U(x, t)}{\partial x}=\Phi(U, x, t)
$$

Similarly, we use the finite difference method and an explicit scheme of the form:

$$
U_{i}^{j+1}=\left(1-\frac{h_{t} B}{2}-\frac{h_{t} C_{0}}{h_{x}}-\frac{h_{t} C_{1}}{h_{x}} U_{i}^{j}\right) U_{i}^{j}+U_{i-1}^{j}\left(\frac{h_{t} C_{0}}{h_{x}}-\frac{h_{t} B}{2}+\frac{h_{t} C_{1}}{h_{x}} U_{i}^{j}\right)
$$


Thus, using the standard procedures of the Python mathematical library and the graphical editor tools, we get numerical solutions, which are shown in fig. 5.
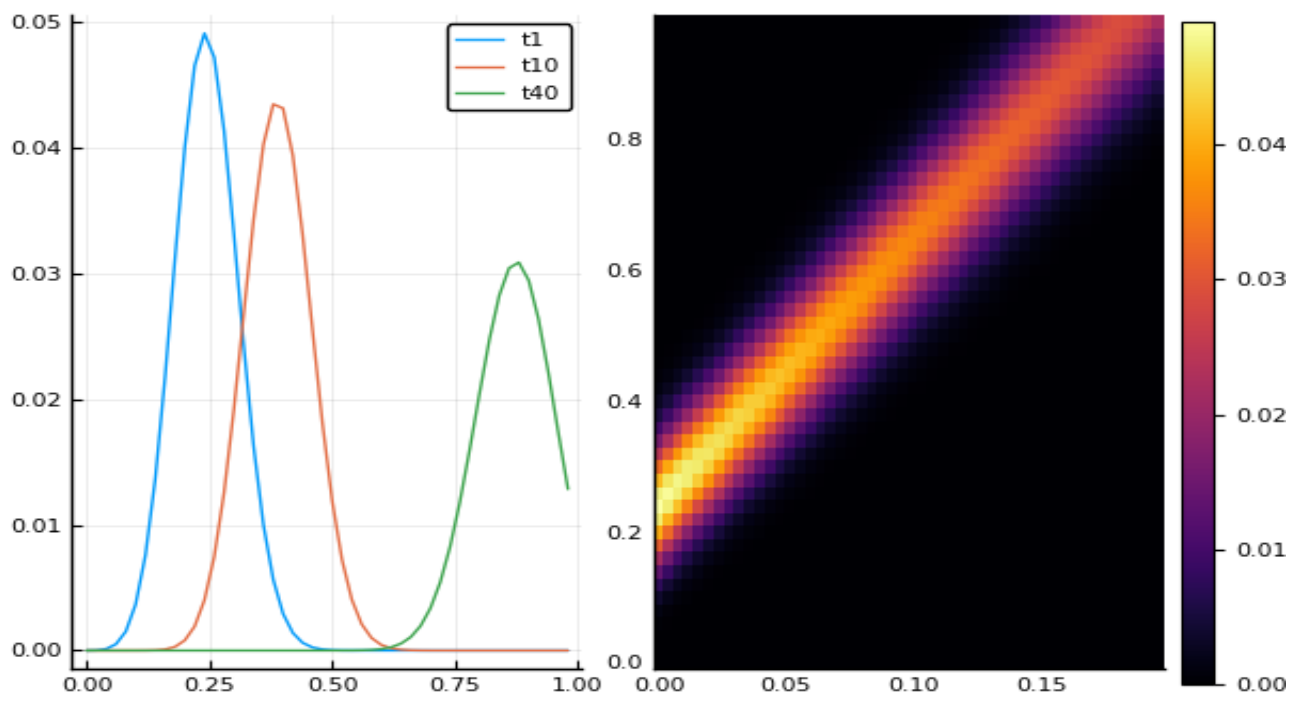

Fig.5. Numerical solutions of the transfer equation for the nonlinear case (at the $\mathrm{y}$ - axis - values of the $\mathrm{u}$ function, at the $\mathrm{x}$-axis is time. On the right is a color map of solution graphs)

Let's review mathematical models of exogenous geological processes that will be modeled by partial differential equations of hyperbolic type:

$$
\frac{\partial^{2} U(x, t)}{\partial t^{2}}=c^{2} \frac{\partial^{2} U(x, t)}{\partial x^{2}}
$$

Using the standard MD procedures of the Python mathematical library and the graphical editor tools, we obtain the following numerical solutions, which are shown in fig. 6 (subspace) and fig. 7 (surface).

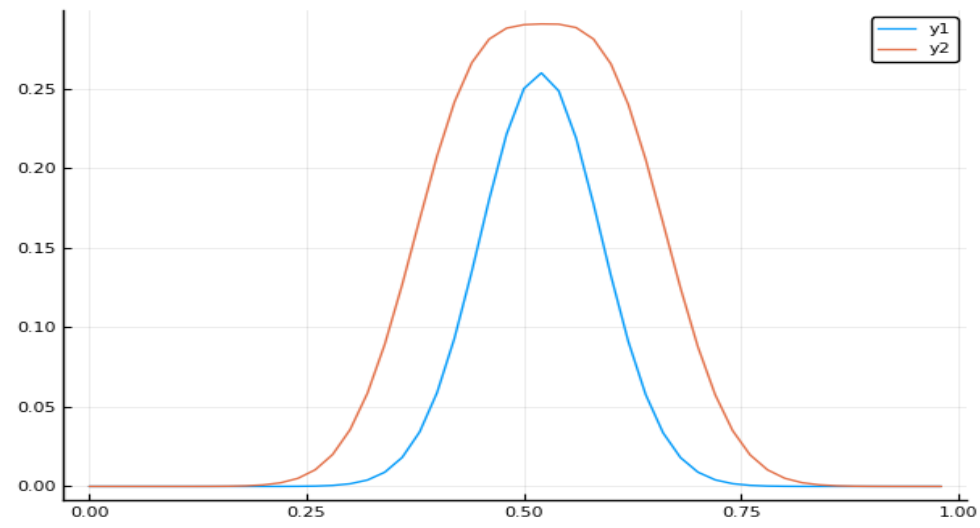

Fig. 6. Numerical solutions of the wave equation (subspace). (at the $y$ - axis - values of the $u$ function, at the $x$-axis-time) 


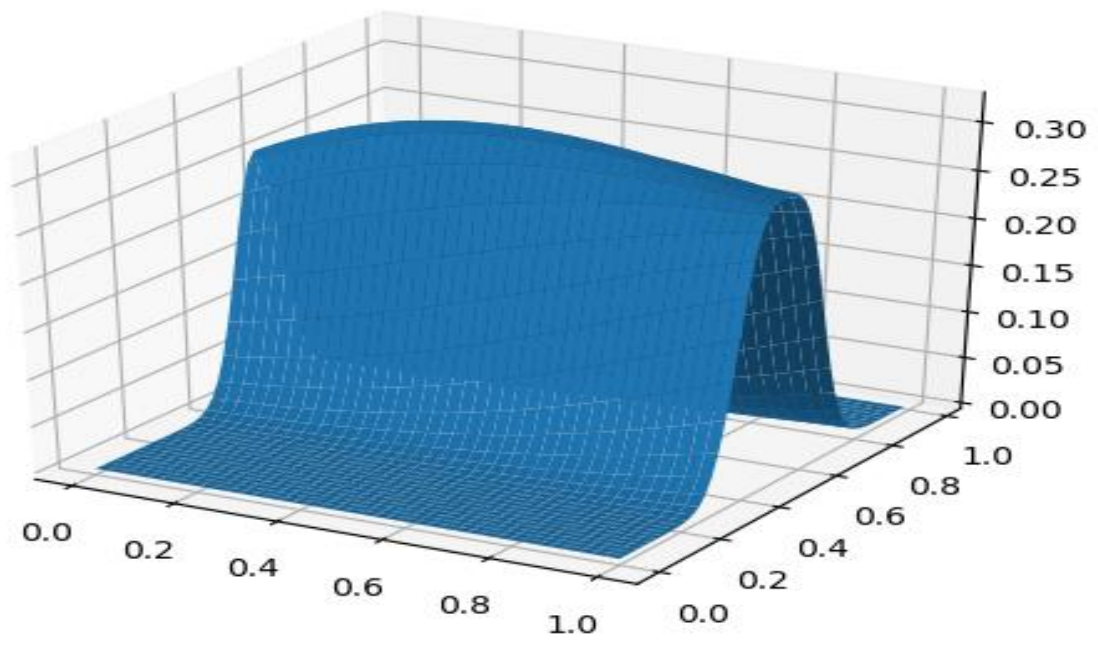

Fig. 7. Numerical solutions of the wave equation (surface)

Thus, for the organization of monitoring of dangerous EGP, mathematical tool has been developed in the form of mathematical models, which are described by second-order partial differential equations of parabolic and hyperbolic types. There are proposed computational algorithms implemented by the Python mathematical library and graphic editors for numerical solution of mathematical models.

\section{Conclusion}

Modern level of scientific research presumes and obliges development and using of new information technologies. In this regard there was defined a problem on mathematical modelling and information technologies using for research and forecasting of EGP on the territory of Kyrgyzstan. There are proposed hydrodynamic models and numerical methods of their solution. Information system is developed for landslides, mudflows, and other EGP types, typical for Kyrgyzstan.

Forecasting models are proposed and based on them short-term an mid-term (for 1-3 years) forecasts of EGP activation on the territory of Kyrgyzstan. Thus and so, the major problem for today is in constant provisioning, updating and upgrading of the web-site, information system and database by means of corresponding information material, clear statistics, formation, development and activation of catastrophic EGP observation data on the territory of Kyrgyzstan.

\section{References}

1. Monitoring, forecasting of dangerous processes and occurrences on the territory of the Kyrgyz Republic. Bulletin of the Ministry of Emergency of the Kyrgyz Republic (Bishkek, 2016)

2. Wordpress documentation. URL https://wordpress.org/support/

3. Byte of Python book. URL https://python.swaroopch.com/stdlib.html

4. D. Krein, E. Paskarello, D. James, MySQL. MySQL Press. 432 (2010)

5. Exogenous geological processes in Kyrgyzstan. URL http://egpkr.go.kg/\# 
6. C.A.J. Fletcher, Computational Techniques for Fluid Dynamics: Fundamental and General Techniques, 1, 401 (1996)

7. O. Tymchenko, E. Ugnenko, R. Makovyey, Procedia Engineering, 134, 146-152 (2016), doi: 10.1016/j.proeng.2016.01.051

8. Bateman Harry, Erdelyi Arthur, Higher transcendental functions, 1, 990 (1953)

9. Marten Geertsema, Lynn Highland, Laura Vaugeouis, Environmental Impact of Landslides (2009) doi: 10.1007/978-3-540-69970-5_31

10. G.Zolotarev, Modern problems of engineering-geological study of landslides, landslides, avalanches and mudflows in mountainous folded areas, 368 (Moscow State University Press, 1976)

11. A.Sherhov, et.al., Calculating of sustainability of the slope by the method of a circlecylindrical surfaces of sliding

12. J. Ferziger, M. Perit, Computational Methods for Fluid Dynamics, 423 (SpringerVerlag, Berlin, Heidelberg, New York, Germany, 2002)

13. S. Biringen, C.-Y. Chow, John Wiley \& Sons, 320 (2011)

14. J. Wendt, Computational Fluid Dynamics: An Introduction, 332 (Berlin Heidelberg, 2009)

15. "Kyrgyzstan" brief statistical handbook. URL http://www.stat.kg/en/publications/kratkij-statisticheskij-spravochnik-kyrgyzstan/ 